\title{
A TROCA DE TERAPEUTAS NOS ATENDIMENTOS PSICANALÍTICOS EM INSTITUIÇÕES
}

\section{THE CHANGE OF THERAPISTS IN PSYCHOANALYTICAL TREATMENTS IN INSTITUTIONS}

\author{
Marcela Casacio FERREIRA ${ }^{1}$
}

\begin{abstract}
RESUMO
O presente trabalho objetiva discutir o uso da técnica psicanalítica nos atendimentos psicoterápicos individuais em clínicas-escolas, com enfoque na troca de terapeutas que possa ocorrer durante este processo. Entendemos que a troca acontece quando é esgotado o prazo do terapeuta na instituição ou mesmo por outros motivos que demandem mudança do profissional. Os pontos de reflexão e discussão do texto são: as diferenças entre um paciente e outro que podem ocorrer no processo de mudança de terapeuta e do estabelecimento de novas transferências, principalmente os psicóticos ou borderlines - estes pacientes podem apresentar grande sofrimento na separação de um terapeuta para se vincular a outro, o que nos faz questionar tais tratamentos; também, a necessidade das instituições em atentarem a esses pacientes, bem como reverem o tempo de permanência tanto dos seus profissionais quanto do paciente em um tratamento psicoterápico.
\end{abstract}

Palavras-chave: troca, psicoterapeuta, psicanálise, instituição, clínica-escola.

\section{SUMMARY}

The present paper discusses the use of the psychoanalytical technique in individual psychotherapy treatment in school-clinics, focusing the change of therapists that may occur during the process. The change happens when the term of the therapist at the institution is over or even for other reasons that require the change of the professional. The items to reflect and discuss over this text are: the probable differences among patients in the process of

(1) Doutoranda da PUC-Campinas e bolsista do CNPq

Correspondência com o autor: Av: Princesa D'Oeste, 1847 - apto. 114 - Jd. Guarani - CEP: 13026431 - Campinas - SP. marcelacasacio@uol.com.br

Endereço para correspondência com o editor: Av: Princesa D'Oeste, 1847 - apto. 114 - Jd. Guarani - CEP: 13026431 - Campinas - SP. Telefone: (019) 3254-1518. marcelacasacio@uol.com.br 


\begin{abstract}
changing therapists and the setting of new transferences, mainly the psychotics or borderlines. It could be painful for these patients to be apart from one therapist and rely on another one. This suffering may raise doubts about the excellence of such treatments. Another item to be taken into account is the attention given by the institutions to these patients, as well as the remaining time of both professionals and patients in the institution.
\end{abstract}

Key words: change, psychotherapist, Psychoanalysis, institution, school-clinic.

A técnica psicanalítica é assunto para muitas discussões, tanto pela importância da sua prática, inclusive em instituições, quanto pela necessidade de seu crescimento científico.

Sabemos que Freud acreditava que o sujeito era o único a saber sobre si e, com a ajuda do analista interpretador, poderia revelar algo e alcançar uma compreensão do quanto suas idéias estavam em consonância com a sua sintomatologia.

O sintoma, por não poder ser consciente, surge como metáfora e carece de um significado; a manutenção desse sintoma inconsciente implica um desgaste de energia do sujeito, característico da neurose. É por meio do acolhimento da verdade implicada no sintoma do sujeito, que se dá a análise.

Para trabalhar a neurose, deve-se, pois, permitir ao paciente falar livremente, sem coerção. É a técnica da associação livre a ser respeitada do lado do paciente e a atenção flutuante do lado do analista, que tem como ferramentas, para buscar o desvelamento do sujeito, o estudo das idéias livremente associadas pelo paciente, por meio da interpretação dos seus sonhos, falhas e ações sintomáticas, causadas, principalmente, pela transferência (FREUD, 1910[1909]/1996).

Se há grande importância do trabalho da transferência durante o tratamento e então, de um vínculo entre analista e paciente na busca do seu desvelamento inconsciente, é preciso pensar nas atuais ocorrências de trabalhos institucionais que permitem uma troca constante de terapeutas entre um período de atendimento e outro, representando um rompimento prematuro dessa relação. O que dizer, também, desses trabalhos institucionais com crianças e com sujeitos de estrutura psicótica ou borderline? Ou, se não quisermos falar em estrutura, dissermos pacientes mais regredidos?

O objetivo do presente trabalho - texto que se configura como parte da tese de doutorado em andamento - é discutir teoricamente o uso da técnica psicanalítica nos atendimentos psicoterápicos individuais em clínicas-escolas, com enfoque na troca de terapeutas que possa ocorrer durante um processo. Entendemos que esta troca acontece quando é esgotado o prazo de um trabalho do terapeuta na instituição ou mesmo por outros motivos que demandem mudança do profissional.

Justifica a inquietude sobre o tema dessa investigação o fato de ocorrer um uso da técnica da psicanálise clássica transposta diretamente a um contexto diferenciado, o que implica divergências quanto ao setting tradicional, já que o vínculo transferencial que acontecia na técnica clássica com um só profissional não ocorre nesses atendimentos institucionais.

Há, pois que se questionar até que ponto os tratamentos que necessitam de longo prazo podem admitir as trocas constantes de terapeutas nas instituições.

\section{O SERVIÇO DE PSICOTERAPIA PARA A COMUNIDADE, HOJE}

Sabemos que essa prática de trocas constantes de terapeutas é a usualmente realizada nas instituições ou, pelo menos, a que temos notícia. Mas há poucos estudos - ou 
quase nenhum - que descrevem e propõem uma alternativa para essa questão.

Realizei um pesquisa bibliográfica sobre este tema, o da situação analítica em instituições relacionada ao fator da mudança do terapeuta e o que observei foi um campo com poucos estudos. Encontrei um artigo de pesquisa que relata uma experiência de mudança de terapeuta e seus possíveis efeitos de LHULLIER et al. 2000.

Este artigo discute o problema da mudança de terapeuta durante o processo psicoterápico, relacionando-o com o alto índice de abandono dos trabalhos psicoterápicos realizados em uma instituição pública. Para analisar tal problemática, uma equipe realizou uma experiência com dois grupos: um grupo com os tratamentos que estavam para encerrar, incluindo, na passagem de um terapeuta para outro, um período de adaptação, que se resumia na presença do terapeuta anterior junto ao atual, em um trabalho de "passagem"; e outro grupo, no qual não houve essa adaptação. Verificou-se que o índice de abandono foi menor no grupo em que houve o trabalho de 'passagem', em relação ao outro grupo (LHULLIER et al. 2000).

Um outro trabalho encontrado foi uma dissertação sobre as transferências de terapeutas que ocorrem em um hospital-escola de Chicago, de LEVENBERG (1999). A autora discute as questões transferenciais e contratransferenciais que permeiam o trabalho nas instituições, atribuindo, respectivamente, uma significância maior à questão da transferência com a equipe e com a instituição, em contraponto com a transferência direta com o terapeuta. Também, destaca a contratransferência da equipe, fator que a autora acredita ser o impulso na tendência desses funcionários a promover uma continuidade do trabalho em busca da cura tanto quanto (ou até maior), do que se tem por objetivo, um trabalho psicoterapêutico individual.

Cabe fazermos aqui uma diferenciação entre Psicoterapia psicanalítica e psicanálise, para que se evite equívocos conceituais. $O$ termo psicoterapia psicanalítica implica a ocorrência da psicanálise em um contexto de setting diferente daquele do século XIX de Freud, dos consultórios particulares, abarcando um tempo definido de trabalho, que se diferencia da 'psicoterapia breve' por não focalizar pontos a serem trabalhados durante o tratamento.

É importante ressaltarmos que a discussão presente não trata de questionar se há possibilidade de ocorrência dessa 'psicanálise' ou de uma situação analítica em um contexto diferenciado. Observamos hoje que, nas instituições, a psicanálise alcançou um espaço para sua realização que permite a instauração de uma situação, mesmo com um enquadre modificado.

É preciso reconhecermos que o analista, se assim se mantiver, poderá criar e manter a situação analítica mesmo que em um setting de condições diferentes. Poderíamos definir a situação analítica como "a condição transferencial e técnica particular capaz de sustentar, face a um sujeito que sofre com seus sintomas, o enigma de seu inconsciente e o desejo de elucidação do saber que supostamente ele comporta" (BUENO e PEREIRA, 2002, p. 16). Esta condição implica a autorização do sujeito para que haja a intervenção do ato analítico independente do setting em que ela ocorra.

LEITE (1995) identifica o enquadre usado por algumas psicoterapias breves, com tempo e espaço modificado, como sendo aquele que não impede a instauração em seu interior de uma situação analítica. Destaca, porém, as dificuldades acarretadas, uma vez que depende de o analista manter-se como tal, já que as condições não são tão favoráveis como as dos consultórios psicanalíticos clássicos. Por outro lado, usando as idéias de GILLIÉRON (1993, apud LEITE, 1995) conta-nos que a limitação do tempo pode muitas vezes acelerar toda a dinâmica do tratamento, o que nos revela um outro lado - positivo - dessa mudança de setting.

FÉDIDA (1998) fala-nos sobre o que está no pensamento do terapeuta e tudo o que permeia entre ele e seu paciente como desvios em relação à regra ideal e geral da psicanálise, 
como os configuradores da prática psicoterápica; embora saiba que fazemos uso - e necessitamos - daquelas regras gerais e fundamentais. Descreve essa regra fundamental como a regra da associação livre do paciente, a regra de atenção equiflutuante do analista (que considera aspectos complementares) e mais uma terceira: a regra da não-intervenção de terceiros.

Mas o que nos interessa aqui, como dito, é de que forma os trabalhos de tempo maior que um ano - pressupondo uma necessidade de continuidade do tratamento do paciente - se sustenta nessas instituições e, principalmente, quando se trata dos pacientes mais regredidos.

Há casos em que, após um ano de atendimento ou mesmo após seis meses, configura-se uma melhora do paciente, dispensando-se a continuidade do tratamento. Para esses casos, consideramos como inócua a discussão. Também podemos pensar que essa entrada no mundo inconsciente pode promover um interesse no paciente de investir na continuidade de uma análise, mas que isso nem sempre é possível. Mas, nos casos nos quais o tratamento ainda carece de tempo para a análise, como as instituições lidam com a situação de troca de profissional?

O campo psicanalítico, como situa ETCHEGOYEN (1989), é o lugar propício para se alcançar a neurose de transferência. Por 'neurose de transferência' compreende-se aquilo que emerge na 'situação analítica', direcionado ao analista, promovido pelos processos regressivos da libido do paciente. A regressão é uma forma de o paciente revelar as marcas deixadas por experiências vividas no passado que não puderam ser elaboradas, resolvidas ou descarregadas e que, quando surgem no setting, representam, para a psicanálise, uma via de compreensão dos pontos de fixação da neurose do paciente, que devem ser analisados e interpretados.

A promoção da 'neurose de transferência' na situação analítica e no tratamento psicoterápico psicanalítico é imprescindível e, mais do que isso, sua manutenção permitirá que o paciente possa compreender o presente, de acordo com suas experiências do passado (FREUD, 1912a/1996). Então, quais são (ou seriam) as circunstâncias necessárias para que ela seja sustentada e mantida?

O fenômeno da transferência representa o desejo do paciente que não pôde ser satisfeito e foi reprimido e que anseia por ser dissolvido através da pessoa do analista. É preciso, então, que este último esteja consciente disso e crie condições para evitar qualquer satisfação por parte da pulsão do paciente, o que seria mais uma repetição e atuação na vida real. Este procedimento é o que proporcionará o trabalho de recordação dos aspectos do psiquismo do paciente, levando-o, se possível, a uma compreensão interna e elaboração do conflito.

Entretanto, para que se promova a transferência, deve existir uma condição própria para isso. A escuta psicanalítica se mostra como algo diferenciador: é por meiodela que a transferência pode ser conquistada. Além disso, é por intermédio da escuta do analista que a transferência é valorizada como fundamental para o trabalho analítico, lembrando que ela pode acontecer em qualquer lugar, mas é na situação analítica que fazemos uso dela.

Faz-se necessário, então, que olhemos para isso sob o foco de uma instituição, em que esse 'enquadre' contenha elementos que o diferencie daquilo originariamente proposto. É a partir dessa inquietude que nasceu essa pesquisa. Por meio de vivências em instituições, experimentando a troca de terapeutas (tanto no papel daquele que acolhe o paciente vindo de seu ex-terapeuta, quanto no que deixa o paciente para um outro), resolviestudar a possível influência dessa prática no tratamento psicoterápico.

Pensemos, agora, sobre esta questão da técnica psicanalítica sob outro ângulo da transferência. Sabemos que Lacan dissecou a transferência apresentada por Freud em duas dimensões: uma, relacionada ao simbólico, que é aquilo que o paciente espera conseguir com 
aquele analista especificamente. Outra, do âmbito do imaginário, que concerne a essa experiência de atualizar aquilo que é antigo (MILLER, 1988).

Assim sendo, Lacan atribui à dimensão simbólica a sustentação da situação analítica. Para ele, deve existir a credibilidade do sujeito no analista. $O$ analista é colocado no lugar do sujeito suposto saber e isso se faz necessário para que o sujeito se mantenha na busca do seu enigma com aquele analista que ele supõe que é o detentor do saber. Sem isso, não há análise, não há implicação. Para ele, se há em algum lugar o sujeito suposto saber, há transferência e há a situação analítica (LACAN, 1964).

Isso não é o mesmo que estar do lado de um discurso sobre a verdade do sujeito, muito menos se identificar com esse lugar do sujeito suposto saber (MILLER, 1988). O analista não será aquele que enunciará a verdade de seu paciente, apenas se manterá na posição daquele que escuta para, então, propiciar ao sujeito o encontro com a sua verdade.

Essa questão nos remete diretamente à demanda que o sujeito apresenta relacionada com seu desejo (LACAN, 1960-1961). O sujeito que coloca o analista no lugar daquele que sabe e que conduzirá o tratamento nos caminhos da cura demanda ajuda e, portanto, ao estabelecer a transferência, ele permite que a situação analítica ocorra. Podemos dizer que esse desejo precisa ser do analista, desejo esse de saber, que pode proporcionar ao paciente o alcance de um conhecimento da sua verdade.

Podemos pensar que a transferência, assim como Lacan nos apresenta, seria vista como aquilo que ocorre entre analista e paciente para a sustentação do atendimento. Então, o que dizer da troca de analista durante um processo psicoterápico?

Estamos dizendo que há, sim, a possibilidade de se criar esse lugar (do sujeito suposto saber) em circunstâncias diferenciadas das clássicas, inclusive em um lugar que já foi ocupado por um terapeuta anterior. Mas é preciso certos cuidados com alguns pacientes que podem apresentar dificuldades na constituição desse tipo de vínculo (que altera a cada período), o que acarretará problemas no trabalho em vez de soluções ou construções.

\section{DE QUE PACIENTES FALAMOS?}

Quem são esses pacientes? Esse é um outro ponto a se discutir. Quando falamos de transferência em contextos de atendimentos comunitários, o que implica uma experiência do paciente em se vincular, vislumbrando a separação futura, precisamos pensar sobre que vínculos são estes e com quem. Entramos em um campo de clínicas diferentes, que sugere que a transferência pode acontecer de diversas maneiras, que nos remete às diferenças entre tratamento psicanalítico com sujeitos neuróticos, psicóticos ou borderlines.

Como dito anteriormente, se não quisermos falar em estruturas psíquicas, podemos pensar em 'pacientes regredidos'. Talvez esta terminologia nos ajudasse a refletir, inclusive, em relação a casos de sujeitos neuróticos com aspectos de extrema fragilidade, ou seja, com questões primitivas de carácter psicótico, que se aproximam daqueles sujeitos regredidos e que não necessariamente recebem de imediato diagnóstico de psicótico ou de 'estado limite'.

Se pensarmos nas questões do setting à maneira que WINNICOTT (1983) descreve os processos de desenvolvimento do bebê - ou seja, que há necessidade de se manter uma confiança no sentido de seqüência, estabilidade e segurança, que é a necessidade de que o bebê não experiencie trocas constantes de cuidadores, isto é, que possa ter um registro de alguém que esteja com ele - o paralelo pode se divergir com a nossa prática clínica. Uma das questões é se o paciente é regredido e, então, assim como nos fala Winnicott, precisaria de um tempo para se vincular com seu cuidador para então passar por todo o processo maturacional em prol do fortalecimento de seu ego, podendo assim atingir uma condição para se frustrar e se preocupar; 0 
que vemos na prática clínica institucional não é isso.

Vemos estagiários ou residentes, que estão cumprindo seus créditos de disciplinas, mas que não podem envolver-se com aqueles pacientes por mais tempo; fica a seu critério permanecer na instituição voluntariamente ou, caso contrário, o vínculo deve ser interrompido. O paciente regredido pode vivenciar essa separação e troca como um abandono, o que talvez fomente a fragilidade de seu ego, o que pode não ajudar em nada o paciente, ou até mesmo prejudicá-lo.

Pude me confrontar com situações desse tipo, quando realizei um estágio para recém-formados em um hospital psiquiátrico público. Vinculei-me com uma paciente adulta, de diagnóstico psicanalítico de neurose histérica que, apesar de apresentar caraterísticas histéricas, podia ser analisada pelos aspectos 'fronteiriços' que apareciam na transferência, permeados de sofrimento pelo rompimento do vínculo com a terapeuta anterior, juntamente com um temor da ameaça de um estabelecimento do novo vínculo comigo.

Após uma difícil caminhada no sentido do estabelecimento da transferência, conseguimos uma aproximação satisfatória, porém, próxima a um novo processo de desligamento. Diante da dificuldade da paciente e sua necessidade da experiência de um vínculo mais duradouro, decidi permanecer na instituição, voluntariamente, por mais um ano. Foi um período muito rico, pois conseguimos trabalhar muitas de suas questões, o que talvez fosse diferente caso ocorresse o repentino rompimento de um vínculo terapêutico.

Como administrar tais situações? É preciso que as instituições e suas clínicas-escolas atentem a essas questões, promovendo um cuidado a esses pacientes que chamamos de 'regredidos'.

Contudo, quanto à freqüência de sessões (o que geralmente acontece uma vez por semana nas instituições públicas), podemos pensar que, mesmo considerando o número de sessões reduzido, é possível mantermos uma freqüência, uma estabilidade dos encontros capaz de viabilizar um registro psíquico do paciente de confiança em relação aos atendimentos, o que evitaria traumas e reorganizações defensivas para lidar com a angústia.

Outra freqüência a ser considerada é o tempo de permanência de um paciente em uma instituição. Por quantos semestres ou anos podemos sustentar o tratamento do paciente? Isto deve ser vinculado ao tempo do profissional e dos atendimentos?

Um sujeito busca a psicoterapia por ser portador de um mal-estar. Esse tratamento, mesmo que aconteça num contexto de clínicaescola pública, representará o espaço no qual esse sujeito poderá encontrar, conhecer, estar em contato com a sua própria verdade; isso o auxiliará a lidar melhor com seus conflitos e suas questões. É algo de extrema riqueza alguém poder contar com um espaço em que suas paixões possam ser ouvidas.

Hoje, quando falamos de psicanálise, estamos nos remetendo a algo amplo cujo termo é plástico, já que pode ser tratado a partir de diversos referenciais e não só do referencial dos consultórios particulares. Vemos diversas formas de sua ocorrência mais coerentes com a situação do nosso país. Nem por isso, perde-se um referencial de trabalho que está em consonância com a postura de se debruçar sobre o sofrimento daquele portador da palavra: a posição da Psicopatologia Fundamental (BERLINK, 2000), por exemplo, que permite um olhar diferenciado ao paciente. Um olhar clínico como da medicina praticada em Atenas, ou mesmo no teatro grego, ambos nos tempos de Péricles: o médico e o espectador do teatro inclinam seus corpos diante de alguém que porta uma voz única a respeito de seu pathos - sofrimento, paixões, passividade (CARVALHO, 1992). Ao manter tal posição e postura, há experiência e esta promove o saber. Isto é clínica: respeita o princípio da voz única que suscita experiência e terapia. (BERLINK, 2000).

A postura quem faz é aquele que acolhe o doente; é aquele que permite o saber e a 
experiência. Usando as palavras de Fédida "a descoberta da psicanálise consiste na possibilidade da experiência interna do que é o psicopatológico, desde que essa experiência interna não se psiquiatrize no sentido de se tornar patologia crônica e nada ensinar àquele que a vive" (FÉDIDA, 1988, p. 29).

Uma personalidade neurótica, que consiga estabelecer uma transferência e, usando-a como instrumento, possa permitir um espaço no qual o analista esteja a ouvidos, certamente será beneficiada por uma psicanálise. Com esses sujeitos, a troca de terapeuta possivelmente poderá ser trabalhada, ouvida, e a transferência retomada, reeditada a cada novo analista.

Para exemplificar, nesse mesmo estágio do qual falei anteriormente, recebi vários pacientes neuróticos que, ao iniciar a psicoterapia comigo, traziam algumas questões da sua terapeuta anterior; entretanto, de forma branda, permitindo um trabalho de luto, de separação, podendo ter em vista um recomeço com uma outra psicoterapeuta.

Mas, como dito, há pacientes - outros, que se diferenciam dos neuróticos - que sofrem com essa transição e, para eles, é preciso rever o trabalho, o que significa rever a permanência, a estabilidade do profissional na instituição, enfim, o tempo da psicoterapia psicanalítica e a questão da troca dos terapeutas nas instituições.

\section{REFERÊNCIAS BIBLIOGRÁFICAS}

BERLINK, M. T. (2000). Psicopatologia Fundamental. São Paulo: Escuta.

BUENO, D. S.; PEREIRA, M. E. C. (2002). Sobre a situação analítica: a experiência de psicoterapia psicanalítica no hospital universitário da Unicamp. Pulsional Revista de Psicanálise, ano XV, 157, 15-24.

CARVALHO, R. M. L. L. (1992). Ludoterapia psicanalítica com crianças e adolescentes institucionalizados. 178f. Tese de doutorado (Faculdade de Ciências Médicas) - Universidade Estadual de Campinas. Campinas, SP.
ETCHEGOYEN, R. H. (1989). Fundamentos da Técnica Psicanalítica. Tradução Cícero G. Fernandes. Porto Alegre: Artes Médicas.

FÉDIDA, P. (1988). A clínica psicanalítica: estudos. São Paulo, Escuta.

FREUD, S . (1910 [1909]). Cinco lições de psicanálise In: Edição Standard Brasileira das Obras Psicológicas Completas de S. Freud, Rio de Janeiro: Imago, v. 11.

A dinâmica da transferência (1912a/1996). In: Edição Standard Brasileira das Obras Psicológicas Completas de Sigmund Freud, Rio de Janeiro: Imago, v. 12.

LACAN, J. (1992). O seminário, livro 8: a transferência (1960-1961). Texto estabelecido por Jacques Alain-Miller. Versão brasileira de Dulce D. Estrada, Rio de Janeiro: Jorge Zahar.

(1985). O seminário, livro11: os quatro conceitos fundamentais da psicanálise (1964). Texto estabelecido por Jacques AlainMiller. Versão brasileira de M. D. Magno, 2. ed. Rio de Janeiro: Jorge Zahar.

LEITE, A.C.C. (1995). Psicoterapia breve e situação analítica: uma leitura crítica e reflexiva. 98 f. Dissertação (Mestrado em Saúde Mental) - Universidade Estadual de Campinas. Campinas, SP.

LEVENBERG, L.S. (1999). The impact of multiple forced transfers in a training institution: Revolving door therapy. Dissertation. Chicago School of Professional Psychology, Chicago.

LHULLIER, A.C. et al. (2000). Mudança de terapeuta e abandono da psicoterapia em uma clínica-escola. Aletheia, 11, 7-11.

MILLER, J.A. (1988). Percurso de Lacan: uma introdução. Tradução Ari Roitman. Rio de Janeiro: Jorge Zahar.

WINNICOTT, D.W. (1983). O ambiente e os processos de maturação: estudos sobre a teoria do desenvolvimento emocional. Tradução Irineo Constantino Schuch Ortiz. Porto Alegre: Artes Médicas.

Recebido para publicação em 9 de dezembro de 2002 e aceito em 12 de maio de 2003. 
